\title{
LA INMEDIATEZ DE LA MUERTE Y SU SIGNIFICADO RACIONAL
}

\author{
Miguel Martí Sánchez \\ Universidad de Navarra
}

\begin{abstract}
Resumen: El presente artículo aclara la tesis de Fernando Inciarte según la cual la muerte en cuanto tal coloca al ser humano ante lo inmediato, es decir, más allá del horizonte que le abre su comprensión mundana. Esta inmediatez, dice Inciarte, es un indicio de que es razonable esperar algo más que la muerte, y por lo tanto que la razón no comete ningún crimen si se abre a la fe. Para contrastar esta idea se acude a la ayuda de la tradición filosófica, sobre todo, aunque no solo, a la fenomenología. A partir de la sucinta exposición de diferentes posturas sobre el morir y la muerte se elabora un discurso unitario sobre su significado para el ser humano. Se demuestra que la postura de Inciarte, lejos de conducir a un fideísmo, se basa más bien en argumentos racionales de validez contrastada.
\end{abstract}

Palabras clave: muerte, inmediatez, fe, razón, filosofía, Inciarte.

\section{The Immediacy of Death and its rational Meaning}

Abstract: The present article clarifies the thesis of Fernando Inciarte according to which death puts the human being in front the immediacy, that is, beyond the horizon that opens his understanding. This immediacy, says Inciarte, is an indication that it is reasonable to expect something more than death, and therefore the reason does not commit any crime if it is opened to faith. In order to contrast this idea, I turn to the help of the philosophical tradition, above all, but not only, to phenomenology. From the brief exposition of different positions on death a 
Miguel Martí

unitary discourse is elaborated on its meaning for the human being. It is shown that Inciarte's position, far from leading to fideism, is rather based on rational arguments.

Keywords: Death, Immediacy, Faith, Reason, Philosophy, Inciarte.

Recibido: 25/5/2017 Aceptado: 10/6/2017

\section{La muerte y el binomio fe y razón}

En la segunda parte del libro Cultura y verdad desarrolla Fernando Inciarte una argumentación centrada en el binomio fe y razón. A raíz del libro de Pirmin Stekeler-Weithofer Hegels analytische Philosophie. Die Wissenschaft der Logik als kritische Theorie der Bedeutung y de la encíclica Fides et ratio de Juan Pablo II elabora, en una larga disertación, la tesis de que en dicho binomio no necesariamente se da una oposición de contradicción, sino que más bien fe y razón se complementan. E1 libro de Stekeler-Weithofer funciona para Inciarte como modelo de un modo de pensar que considera la fe como algo irracional y místico sin ningún tipo de vinculación con la razón. En este sentido la lógica de Hegel (su metafísica, dice Inciarte) sería el culmen del pensamiento y si este excluye la fe entonces es que esta no es racional. En cambio, el segundo libro es para Inciarte el paradigma de la apuesta perenne de la Iglesia católica —aunque no solo de esta— por la razón $y$ la fe, al mismo tiempo que una defensa de su compatibilidad sin ceder al racionalismo y al fideísmo. Inciarte busca en dicho diálogo entre un racionalismo excluyente y la postura compatibilista de la encíclica papal no perder lo que de verdadero se da en las dos posibilidades. 
El problema de fondo reside en qué tipo de relación se da entre fe y razón. $\mathrm{Si}$, por un lado, se afirma, como hace la encíclica papal, que la fe eleva la razón queda por decidir qué tipo de razón y qué tipo de limitación sería necesario subsanar; si, por otro lado, se afirma que la fe no es en definitiva racional, quedará por demostrar que solo con la razón se comprender cualquier fenómeno, pues lo contrario es abrir la puerta a la irracionalidad. En definitiva, depende del concepto de razón que se defienda la fe aparece como una prolongación de la razón o como un residuo de irracionalidad.

A juicio de Inciarte, determinadas realidades o acontecimientos que se dan en la vida exigen a la razón demasiado para ella, es decir, la sobrepasan, sin ser en cambio algo irracional. A tales acontecimientos los cataloga Inciarte como inmediatos en el sentido de no subsumibles bajo conceptos mediaciones- de la razón. A partir de ahí, argumenta Inciarte, si la vida o realidad siempre se encuentra más acá de las elaboraciones más profundas de la razón cabría pensar que un saber de lo inmediato en cuanto inmediato no sería superfluo y tampoco irracional. El caso quizá más característico de este tipo de realidades inmediatas es, para Inciarte, la muerte.

Inciarte considera que existe una conexión entre metafísica o conocimiento racional por antonomasia, muerte y fe. La metafísica, dice, en cuanto constructo racional que pretende explicar de modo radical la realidad cuando intenta comprender la muerte se topa con un problema real pero irresoluble mediante la mera razón. En la medida en que ese enigma parece resistir cualquier embate racional deja a la razón ante la siguientes opciones: no aceptar tal limitación e intentar solucionarlo mediante alguna construcción teórica, desistir de una solución y rendirse a su incomprensibilidad y por último, re- 
conocer dicho límite ir más allá de la razón en busca de una respuesta satisfactoria. ${ }^{1}$

En Cultura y verdad Inciarte ensaya una argumentación sobre este punto y dice:

Como lo más subjetivo y a la vez lo más objetivo de la vida humana, la muerte hace que la probabilidad de dar con sustancias reales aumente al pasar de los reinos mineral, vegetal y animal al reino de los seres humanos. Aristóteles indica varias veces que hay algo en el ser humano de lo que no se puede excluir que sobreviva a su muerte. Y como es en la vida misma del hombre donde su muerte ocurre, es ella en esa su máxima inmediatez la que mantiene abierta la puerta a otra posible inmediatez que la trascienda y con la que ya en vida estaríamos en contacto por la fe, (Inciarte, 2016: 212).

Con otras palabras, la muerte no sería solo un límite para la razón sino que en ese mismo límite se le muestra a la razón una posibilidad, a saber: que no todo esté accesible para ella y con ello que no todo lo real se termina con lo que es cognoscible para ella en esta vida. El argumento, sin embargo, es algo oscuro. ¿Cómo es capaz la razón de ver algo positivo en su propio límite?

Si la muerte es un enigma irresoluble para la razón debe ser de un tipo que no liquide de raíz su intento de comprensión. Esto se debe, sugiero, a que en ese límite la razón se juega su propia supervivencia; o bien consigue

${ }^{1}$ El primero sería el caso de la metafísica hegeliana, el segundo la postura de Epicuro y sus seguidores, y por último la tesis de Inciarte. 
alguna respuesta, o bien debe vivir en la perplejidad y aceptar su sino. Pues tal límite, en cuanto término supone una tragedia para la razón porque de él se deriva su finitud constitutiva.

Inciarte intenta responder a esta aporía que presenta la muerte para la razón, y lo hace mediante la sugerencia de que la muerte en cuanto límite y enigma es una oportunidad para abrirse más allá de la experiencia racional. Esa apertura no es, sin embargo, un salto al vacío. Aunque tampoco se trata de un acceso racional a un tipo de experiencia. Según Inciarte, la muerte en cuanto acontecimiento inmediato y por tanto, en cierto sentido, no-racional, gatilla el interés de la razón por un más allá del mundo experienciable. Sobre ese más allá, dice Inciarte, es sobre el que habla la fe, y por ello, es posible sin caer en el fideísmo una prolongación de la razón mediante la fe.

$\mathrm{Si}$ bien es cierto que la interpretación del significado de la muerte que hace Inciarte es original en varios puntos, con el fin de hacer más accesible su argumentación presento diversas tesis que corroboran esta interpretación de la muerte como apertura de posibilidades. Se responde a la pregunta general siguiente: ¿en qué sentido la inmediatez de la muerte coloca a la razón ante un límite que le abriría a la posibilidad de la fe como una prolongación de su finitud constitutiva?

\section{Muerte: inmediata, subjetiva y objetiva}

La muerte puede entenderse, según la tradición filosófica, en sentido objetivo y subjetivo, aunque tanto el uno como el otro entroncan con la muerte como un tema vital. No en el sentido "vitalista", es decir, como si de nuevo se 
tratara de un tema teórico, sino en cuanto que tiene que ver con que el ser humano está vivo y existe. Antes de cualquier opinión o tesis sobre la muerte está el hecho bruto e inmediato que es morirse, y junto a él la reacción originaria del ser humano ante ese hecho, lo que J. Vicente ha llamado el "horror de morir" (J. Vicente 1992). No se trata de que el ser humano sepa teóricamente que la muerte también le afecta a él en algún sentido - como si se pudiese saber de la propia muerte en abstracto- sino que tiene la certeza de que sí síla muerte también llegará para él.

Que la muerte es algo objetivo, en el sentido de hecho bruto, es algo evidente; al menos para aquellos que han llegado al uso de razón. Cabría decir que igual que los animales y los niños para Aristóteles a diferencia del ser humano adulto no pueden ser felices, así tampoco saben que van a morir como en cambio sí lo sabe este último. No es en cambio algo manifiesto en cuanto a su sentido subjetivo. Como dejó escrito de manera magistral Martin Heidegger se puede saber de 'la muerte' sin saber en cambio de 'mi muerte'. Aunque "nadie puede tomarle al otro su morir" (M. Heidegger 1999: 257) sí puede ocurrir que se llegue a caer en la ignorancia de que son otros los que se mueren y no uno mismo. No obstante, lo sepa o lo pase por alto la posibilidad de la muerte configura esencialmente al Dasein. Ya en una conferencia dictada en Marburgo en el año 1924 explicaba que esta posibilidad es para el ser humano la posibilidad de posibilidades, sin la cual el ser humano sería incapaz de entenderse a sí mismo. Dice el pensador alemán que:

El final de mi existencia, mi muerte, no es algo que interrumpa una secuencia de acontecimientos, sino una posibilidad conocida de una manera u otra por el ser- 
La inmediatez de la muerte y su significado racional

ahí: la posibilidad más extrema de sí mismo, que él puede abrazar, apropiársela en su aproximarse. El ser-ahí tiene en sí mismo la posibilidad de encontrarse con su muerte como la posibilidad más extrema de sí mismo. Esta posibilidad más extrema de ser tiene el carácter de lo que se aproxima con certeza, y esta certeza está caracterizada a su vez por una indeterminación absoluta. La propia interpretación del ser-ahí, que sobrepasa a cualquier otra en certeza y propiedad, es la interpretación de cara a su muerte, la certeza indeterminada de la más propia posibilidad del-ser-relativamente-al-fin (Heidegger, 2011: 43).

De ahí que llamase al ser humano o Dasein como ser-hacia-la-muerte (Sein-zum-Tode), no en el sentido de que está para la muerte — como si fuese el término o telos de su vivir- sino porque la muerte configura transversalmente su vivir, como afirma en Ser y tiempo esto se le muestra en la disposición afectiva de la angustia ante la muerte como posibilidad:

La condición de arrojado en la muerte se le hace patente [al Dasein] en la forma más originaria y penetrante en la disposición afectiva de la angustia. La angustia ante la muerte es angustia «ante» el más propio, irrespectivo e insuperable poder-ser. $\mathrm{El}$ «ante qué» de esta angustia es el estar-en-el-mundo mismo. $\mathrm{El}$ "por qué» de esta angustia es el poder-ser radical del Dasein. La angustia ante la muerte no debe confundirse con el miedo a dejar de vivir. Ella no es un estado de ánimo cualquiera, ni una accidental «flaqueza» del individuo, sino, como disposición afectiva fundamental del Dasein, la apertura al hecho de que el Dasein existe como un arrojado estar vuelto hacia su fin, (Heidegger, 2009: 267-268). 
También en sintonía con la tradición fenomenológica inaugurada por Edmund Husserl llegó a una conclusión parecida Max Scheler. En su escrito titulado Muerte y supervivencia sostuvo que:

La muerte no es, por tanto, simplemente una parte empírica de nuestra experiencia, sino que es de esencia de la experiencia de toda la vida, inclusive de la nuestra propia, el hallarse dirigida hacia la muerte. La muerte pertenece a la forma y a la estructura únicas en que nos está dada cualquier vida, la nuestra como otra cualquiera, y esto desde dentro y desde fuera. No es un marco casualmente añadido al cuadro de cada uno de los procesos psíquicos o fisiológicos, sino un marco que pertenece al cuadro mismo, y sin el cual no sería el cuadro de una vida (Scheler 2001: 27).

Tanto Scheler como Heidegger ponen el acento en la muerte como un acontecimiento subjetivo. La muerte en sentido subjetivo aparece como una posibilidad esencial de la experiencia humana. Para el pensador de Marburgo el Dasein es lo que es porque está vuelto hacia la muerte. A su vez para Scheler la vida del ser humano está atravesada por la esencia de la muerte; el mismo proceso de envejecer es notado por el ser humano como una pérdida del tiempo y como un continuo gastarse del mismo. Esta subjetividad de la muerte no significa, como podría entenderse vulgarmente, que la muerte no es objetiva, sino más bien que dicha objetividad si se entiende por ello realidad se muestra en su forma más radical en la interioridad del sujeto racional. De ahí que quepa decir que la muerte es "lo más subjetivo" de la vida como afirma Inciarte. 
Esta perspectiva subjetiva no agota lo que cabe decir de la muerte. No solo porque cabe una perspectiva objetiva a la que también no hemos referido sino porque dicha objetividad en susceptible de distintos abordajes metódicos (biológico, sociológico, antropológico, metafísico, etc.). Con el fin de complementar la visión subjetiva de la muerte diremos algo de su perspectiva objetiva. Dentro de esa pluralidad nos serviremos de la que consideramos más profunda, a saber: la metafísica u ontológica. ${ }^{2} \mathrm{Al}$ mismo tiempo tal perspectiva es a la que Inciarte parece referirse cuando habla de la muerte como «lo más objetivo y más subjetivo de la vida». Pues bien, ¿en qué sentido puede decirse que la muerte es lo más objetivo de la vida?

'Objetivo' es de esas palabras que se dicen de muchas maneras. Algo 'objetivo' puede decirse de: (1) lo que es observable y verificable por cualquiera; (2) lo que no ofrece dudas; (3) lo que está más allá de la opinión subjetiva; (4) aquello que es un hecho más allá de interpretaciones, etcétera. Sin embargo si se intenta clarificar u ordenar estas diferentes acepciones se puede concluir que lo 'objetivo' es aquello ante lo que el sujeto o lo subjetivo queda al margen. $\mathrm{Y}$ con la muerte eso es cierto, ante ella el sujeto solo padece. Con precisión se diría

${ }^{2}$ J. Vicente dice en su artículo "Sobre la muerte y el morir" (J. Vicente 1990/1: 114-115) que caben cuatro accesos a la muerte del ser humano: exterior objetivo, exterior subjetivo, interior objetivo e interior subjetivo y que los cuatro son complementarios y necesarios. No comparto en su totalidad esa visión porque parte de una división anterior que a mi juicio no hace justicia a la unidad previa que es el ser humano. No obstante es una posible diferenciación que ilumina y que de hecho pone en evidencia la limitación de las diferentes perspectivas que se adopten. Dentro de esa clasificación mi acercamiento será a partir de la interioridad objetiva o la metafísica tal y como él la califica. 
que la muerte en cuanto algo objetivo se sufre en el sentido de que es algo que el sujeto no puede más que recibir pasivamente. De ahí que la muerte no sea una acción o acto del sujeto, ni siquiera en el caso del suicidio, porque en ese caso se adelanta la pasión pero se sufre la muerte de igual modo.

Se puede ahora acotar la pregunta acerca de la objetividad de la muerte con la siguiente cuestión: ¿Qué es lo que padece el sujeto cuando muere? Apoyado en la tradición filosófica de orientación platónica y aristotélica se suele definir la muerte del ser humano de dos modos: Como (1) privación de las operaciones vitales o cesación de la vida; y en segundo lugar como (2) separación del alma del cuerpo.

Se añaden así al término 'pasión' los conceptos de 'privación', 'cesación' y 'separación'. En los cuatro casos se hace referencia a que algo que se poseía y se pierde por completo a causa de un cambio radical recibido de modo pasivo. En la primera definición se dice que lo que se pierde es la vida, por su parte en la segunda es el alma. Si se tiene en cuenta que Aristóteles afirmaban que el alma es el principio de operaciones vitales de un cuerpo organizado, hay en ese sentido una correspondencia estricta entre poseer alma y estar vivo. E1 alma para el estagirita no estaba circunscrita al ser humano y no estaba vinculada con una concepción religiosa o teológica. Si, por otra parte, siguiendo a Platón se tiene en cuenta que el alma se identificaba sin reservas con lo humano, entonces lo que se pierde con la muerte es propiamente el cuerpo. Según estas dos definiciones de la muerte esta es en cierto sentido algo natural, ya sea porque desaparece la vida o porque se corrompe el cuerpo, y con él la posibilidad de seguir vivo. Y si la vida se termina como cualquier otro proceso que tiene un inicio en el tiempo y la generación y la corrupción son, en 
el universo, dos caras de la misma moneda, en cuanto acontecimiento natural la muerte es "lo más objetivo" de la vida.

Estas dos perspectivas de la muerte son tenidas en cuenta por Inciarte cuando hace la afirmación que se glosa. No solo hay una certeza de la muerte como algo que me sucederá (sentido subjetivo de la muerte) sino que sé que si algo está vivo tiene que morir (sentido objetivo de la muerte), y que si no muriese entonces algo inesperado estaría ocurriendo. La muerte podría decirse es algo serio y para tomarse en serio. Se trata de algo serio porque cuando ocurre se separa lo que estaba unido - alma y cuerpo de modo- definitivo e irreversible. La pérdida no es momentánea o parcial sino total y para siempre. Además a esto se añade la conciencia o saber del morir propio y por tanto de que me afectará a mí esa misma pérdida definitiva. En ese sentido la muerte es tanto lo más objetivo como lo más subjetivo de la vida.

\section{La finitud de la razón y la muerte}

Citábamos al comienzo que Inciarte no solo se refiere a la muerte en su aspecto que podríamos denominar negativo, es decir, en cuanto que ya sea de modo subjetivo u objetivo le quita a algo al ser humano sino que a juicio del pensador vasco también le abre algo: la posibilidad de la fe. Y esto, como decíamos, asentado en que la muerte desvela algo a la razón. ¿En qué consiste ese desvelamiento?

En relación este desvelamiento inherente a la muerte Joseph Pieper afirma lo siguiente: 
La muerte no es un puro fenómeno natural y menos que nada una liberación del alma de las cárceles del cuerpo; sino que es la disolución brutal de una unidad viviente, la destrucción del hombre como realmente existe. Pero la amargura, el mal (malum) que representa la muerte, eso que no debería ser, no radica solamente, y no siquiera de forma primaria, en el dolor y en el miedo que acongojan al hombre en ese trance, sino en el desarreglo que la muerte supone para la razón humana que, en su función cognoscitiva, indaga por el sentido de la existencia, para el hombre como ser espiritual. El ser cognoscitivo que se ve enfrentado a la muerte descubre toda su amargura cuando se sabe con perfecto derecho a decir, a la vista de ella, que la estructura y situación del ser, en virtud de la cual el hombre debe morir, es algo que no está en orden. $\mathrm{Y}$ en realidad tiene razón, aunque la muerte sea una consecuencia de algo que no debió ser (Pieper, 1970: 90-91).

El desarreglo del que habla Pieper afecta de manera directa a la razón humana. El pensador alemán tiene en cuenta también el sentido objetivo de la muerte - el mal que representa en cuanto privación y separación - pero va más allá al señalar que la muerte pone en tensión a la razón. La razón humana ve en la muerte algo que no está en orden pero, por así decir, no tiene palabra sobre ello. La muerte antecede a la razón en el sentido de que esta se encuentra con aquella como algo necesario. Por lo tanto, a la necesidad natural de la muerte se añade también su necesidad supranatural, o al menos aracional. En el caso de la muerte en sentido objetivo se da una constatación de su necesidad, en cambio, cuando se trata de la muerte en sentido subjetivo 
dicha necesidad es como un dique contra el que la razón irrumpe una y otra vez sin conseguir romperlo.

Estos dos modos en que la muerte se da en la vida -objetivo y subjetivo- - son los que subraya Inciarte. Además, dice él, la inmediatez propia de la vida se intensifica en la muerte, pues en la muerte estamos ante la muestra más pura de que la vida es real y esto significa que no es mental ni es subsumible en la conciencia de algo o alguien. En ese sentido el pensamiento llega tarde siempre, y no solo a la vida sino a su posibilidad más propia la muerte. Si la muerte coloca al pensamiento ante su límite entonces lo real aparece con toda su fuerza, o mejor con toda su inmediatez. En consecuencia si la muerte es un límite entonces lo que se relacione de modo directo con ella, es decir, surja de la muerte como una rama del tronco de un árbol, no es sino una manifestación más de la limitación inherente a todo pensamiento y algo contra lo que él no puede elevarse. Y según Inciarte este es también el caso de la $f e$. Del mismo modo que el pensamiento no puede con la muerte tampoco puede con la fe que surge ante el enigma de la muerte misma. ${ }^{3}$

Es la misma negatividad inherente a la muerte - muerte como privación, separación, cesación - y que se vuelve contra la razón humana — su ser incomprensible - la que, a juicio de Inciarte, puede abrirle otras formas de conocimiento como sería el caso de la fe. Desde esta perspectiva en la que la fe es también un tipo de comprensión aparece la siguiente paradoja: solo la razón que se reconoce finita está en condiciones de seguir siendo razón y por

${ }^{3}$ Las religiones naturales — sin necesidad de fe sobrenatural一, podría argumentarse, surgen también como posibles respuestas al problema de la muerte. 
ende racional. En el caso de que tal reconocimiento no se produjera la razón se entendería a sí misma como infinita, y en tal caso debería ser capaz de englobar la vida y todo lo que en ella se da, incluida la muerte. Pero, como hemos visto, la muerte es una inmediatez irrecuperable para la razón, luego o bien la razón acepta la limitación que la muerte le impone, o bien se torna inevitablemente irracional. En cambio si la razón acepta esa limitación inherente a su propio ejercicio - solo mientras está viva puede conocer- se hace capaz de seguir comprendiendo. En esta segunda opción reside la paradoja: cuando la razón renuncia a comprender más allá de su límite se mantiene en su ser, si en cambio intenta ir más allá tropieza una y otra vez contra un muro insalvable.

\section{La incognoscibilidad de la muerte y la fe como posibilidad}

Hemos visto que la muerte es un límite para el pensamiento. Lo que limita es aquello que abre un mundo de posibilidades. En ese sentido la muerte delimita la vida del ser humano a modo de horizonte que la hace posible dentro de su transcurrir cotidiano. En el caso de la razón son la vida y por tanto la muerte la que le abre sus posibilidades. Tras la muerte la razón terminaría también su actividad. Sin embargo la razón en cuanto que indaga más allá de las apariencias y puede preguntarse por el fundamento de los fenómenos está capacitada prima facie para no sucumbir cuando llegue el momento de morir.

En su trabajo sobre la muerte dice Pieper que: 
La inmediatez de la muerte y su significado racional

En la descripción misma de la muerte se abre de forma inevitable un interrogante acerca de la indestructibilidad del alma y su carácter imperecedero. Entiéndase esto de la manera que se quiera: el hecho es que en la muerte está planteada la problemática de aquello que, en la generalidad de los vivientes y con expresión no demasiado feliz se ha venido en llamar la «inmortalidad» del hombre (Pieper, 1970: 165)

No se trata de un argumento a favor de la inmortalidad del alma, sino más bien de la legitimidad de la pregunta por dicha inmortalidad. En sintonía con el argumento de Inciarte, señala aquí Pieper que la muerte pone contra la cuerdas a la razón. No solo porque la incita a buscar respuestas o soluciones a su posible desaparición con el advenimiento de la muerte, sino porque además es la misma razón la que reconoce la falta de dichas respuestas. La cuestión no es si existen o no argumentos a favor o en contra de la inmortalidad del alma o el intelecto tras la muerte, sino de que exista la posibilidad de buscar tales argumentos. Esta última posibilidad es la que interesa a Inciarte. Porque esa posibilidad no es, en cierto sentido, racional. Lo racional en el caso de la muerte es aceptar su incondicionalidad e inmediatez. No en el sentido de conformarse con ella como algo inevitable, sino de aceptar la limitación de la razón y por tanto dirigirla a la búsqueda de nuevas posibilidades que no sean solo racionales. Es en este punto, es decir, junto al límite y finitud de la razón donde aparece la fe como posibilidad.

Lo que Inciarte trata de decir con el argumento que señalábamos al comienzo es que la incognoscibilidad de la muerte - en el sentido de ser inmediata y por tanto previa a las mediaciones que introduce la razón- abre 
la posibilidad de la fe, y que afirmar lo contrario es ya intentar ir más allá del límite inherente a la razón humana. De ahí que en su opinión exista una conexión intrínseca entre el tipo de ontología o metafísica que se sostenga y la concepción de la razón que también se mantiene, La metafísica que no acepta la inmediatez de la muerte y por tanto su antecedencia a la razón, suplanta dicha anterioridad por la de la razón y por tanto debe dar cuenta de qué ocurre con ella tras la muerte, o bien quitarle toda su importancia a la muerte, cosa que a primera vista es de una total irracionalidad. En cambio, la metafísica que acepta la muerte como algo inmediato se sitúa en la cordura de la razón porque no la obliga a rebasar su límite. Ese límite una vez aceptado sitúa a la razón en condiciones de ver la fe como una posibilidad dentro de sí misma.

En el rechazo de la fe por parte del racionalismo subyace una negación de la inmediatez de la vida y por ende de la muerte. A juicio de Inciarte, solo se puede sostener que algo como la inmediatez no existe si se piensa que la objetividad máxima es la del pensamiento desvinculado de la influencia de la subjetividad, o que dicha subjetividad es la fuente de toda objetividad; es decir, o bien que la realidad consiste en un desenvolverse de la subjetividad en el mundo y por tanto mediante sucesivas mediaciones, o bien que la realidad sea una totalidad mostrenca sin sustancias reales y separadas. En sus propias palabras:

El punto principal es que, por decirlo de algún modo, dentro de los muros de la filosofía en general y de la metafísica en especial, el holismo sustancial deja un portillo abierto a la fe y, con ello, a la posibilidad de un acceso inmediato a la vida 
y a la realidad, mientras que el holismo total, por definición, mantiene ese portillo cerrado" (Inciarte, 2016: 208).

En conclusión, si se acepta la inmediatez de la muerte y por tanto algo irreductible para la razón, entonces dicho límite se convierte en una oportunidad de trascender la razón que se abre a la posibilidad de la fe. Ahora bien, para ello es necesario aceptar la inmediatez de algunas realidades y su esencial ininteligibilidad y por consiguiente admitir a su vez la finitud constitutiva de la razón.

\section{Bibliografia empleada}

Aristóteles, Metafísica. Edición trilingüe de V. García Yebra. Madrid, Gredos, 1998.

M. Heidegger, M., Ser y tiempo, Madrid, Trotta, $2009^{2}$.

—, El concepto de tiempo, Madrid, Trotta 2011.

F. Inciarte, Tiempo, sustancia, lenguaje. Ensayos de metafísica, ed. L. Flamarique, Pamplona, Eunsa, 2004.

-, La imaginación trascendental en la vida, el arte y la filosofía, ed. M.A. Labrada, Pamplona, Eunsa, 2012.

-, Cultura y verdad. Sobre lo objetivo y lo subjetivo en el arte, la vida y la filosofía, ed. L. Flamarique, Pamplona, Eunsa, 2016.

F. Inciarte-A. Llano, Metafísica tras el final de la metafisica, Madrid, Ediciones Cristiandad, 2008.

P-L. Landsberg, Ensayo sobre la experiencia de la muerte. El problema moral del suicidio, Madrid, Caparrós Editores, 1995.

L. F. Mateo Seco, "El concepto de muerte en la doctrina de santo Tomás de Aquino", en: Scripta Theologica, 1974 (6), pp. 173-208. 
Miguel Martí

J. I. Murillo, El valor revelador de la muerte, Pamplona, Cuadernos de Anuario Filosófico, n. 74, 1999.

J. Pieper, Muerte e inmortalidad, Barcelona, Herder, 1970.

Platón, Fedón. Trad., notas, e introd. de Alejandro G. Vigo. Buenos Aires, Colihue, 2009.

L. Polo, Quién es el hombre. Un espíritu en el tiempo, Eunsa, Pamplona, 2015.

R. Rodríguez, (ed.), Ser y tiempo de Martin Heidegger. Un comentario fenomenológico, Madrid, Tecnos, 2015.

J. I. Saranyana, "Sobre la muerte y el alma separada", en: Scripta Theologica, 1980/2 (12), pp. 593-616

M. Scheler, Muerte y supervivencia. Traducción de Xavier Zubiri. Madrid, Encuentro, 2001.

J. Vicente, "Sobre la muerte y el morir", en: Scripta Theologica, 1990/1 (22), pp. 113-143.

—, El horror de morir, Barcelona, Tibidabo Ediciones, 1992.

Miguel Martí Sánchez mmarti.1@alumni.unav.es 